\title{
DÜBLIN
}

Technological University Dublin

ARROW@TU Dublin

\section{Effect of Motion on the ADC Quantification Accuracy of Whole- Body DWIBS}

\author{
A. Stone \\ St. James's Hospital \\ Jacinta Browne \\ Technological University Dublin, jacinta.browne@tudublin.ie \\ Brian Lennon \\ St. James's Hospital
}

See next page for additional authors

Follow this and additional works at: https://arrow.tudublin.ie/scschphyart

Part of the Physics Commons

\section{Recommended Citation \\ Stone, A.J., Browne, J.E., Lennon, B., Meaney, J.F., Fagan, A.J.:Effect of Motion on the ADC Quantification Accuracy of Whole-Body DWIBS. MAGMA, Vol. 25, 4, 2012, p. 263-6. doi:10.1007/s10334-012-0311-1}

This Article is brought to you for free and open access by the School of Physics \& Clinical \& Optometric Science at ARROW@TU Dublin. It has been accepted for inclusion in Articles by an authorized administrator of ARROW@TU Dublin. For more information, please contact arrow.admin@tudublin.ie, aisling.coyne@tudublin.ie, gerard.connolly@tudublin.ie.

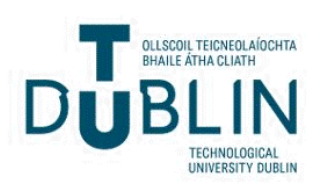


Authors

A. Stone, Jacinta Browne, Brian Lennon, James Meaney, and Andrew Fagan

This article is available at ARROW@TU Dublin: https://arrow.tudublin.ie/scschphyart/55 
Title:

\section{Effect of Motion on the ADC Quantification accuracy of Whole-Body DWIBS}

\section{Authors}

Communicating Author:

A.J. Stone ${ }^{1,2}$, e-mail address: stonea9@cf.ac.uk

A.J. Stone ${ }^{1,2}$, J. E. Browne ${ }^{3}$, B. Lennon ${ }^{4}$, J. F. Meaney ${ }^{1}$, A.J. Fagan ${ }^{1,4}$

Affiliations:

${ }^{1}$ Centre for Advanced Medical Imaging (CAMI), St. James's Hospital / Trinity College, University of Dublin, Ireland,

${ }^{2}$ Cardiff University Brain Research Imaging Centre (CUBRIC), School of Psychology, Cardiff, United Kingdom,

${ }^{3}$ School of Physics, Dublin Institute of Technology, Dublin, Ireland,

${ }^{4}$ Dept. Medical Physics and Bioengineering, St. James's Hospital, Dublin, Ireland

Word count abstract: 100

Word count main text: 1762

3 figures and 11 references. 
Abstract:

Background \& Methods:

Diffusion-weighted whole-body imaging with background body signal subtraction (DWIBS) was introduced as a qualitative approach to detecting metastases in the body. A liver-mimicking phantom with embedded tumours, which could be moved to replicate respiratory motion, was developed to assess its ability to accurately quantify $A D C$ values.

Results:

Mean tumour ADC values were unaltered by the motion; however a significant $(p<0.05)$ increase in the spread of $A D C$ values was measured, even for relatively large tumours.

Conclusions:

These findings may be of significance in cancer therapy monitoring where subtle changes in ADC histograms may reveal changes in tumour heterogeneity. 
INTRODUCTION:

The diffusion-weighted whole-body imaging with background body signal suppression (DWIBS) technique was introduced in 2004 by Takahara et al [1,2] . It applies DWI principles throughout the body, allowing for visualisation and detection of pathological lesions from healthy tissue due to differing diffusion characteristics. DWIBS differs from other DWI techniques as it is acquired during free breathing, and per unit imaging time it favours the use of signal averaging rather than the acquisition of multiple b-values. Typically only two b-values ( 0 and $800-1000$ $\mathrm{s} / \mathrm{mm}^{2}$ ) are acquired, providing good background body signal suppression in the high b-value images in a reasonable acquisition time. DWIBS may be especially useful in the detection of relatively small lesions, of the order of millimetres, due to its high contrast to noise ratio (CNR).

It was originally believed that image contrast would be lost in WB-DWI during free breathing due to respiratory motion. Consequently, breath-holding or respiratory triggering approaches were deemed necessary in torso and abdominal areas. However, since respiratory motion may be considered to be an intravoxel coherent motion, the signal acquired at the various b-values is not affected [3] and the freebreathing DWIBS technique has been successfully demonstrated in several studies [4-7]. However, the effects of increased motion-induced partial volume effect (PVE) on the detection and characterisation of lesions using DWIBS has not been investigated in detail and may lead to non-detection or misdiagnosis of small lesions or lesions exhibiting significant heterogeneity [7]. This has particular relevance given 
the push to quantify DWIBS-derived ADC values for use in staging, monitoring response to therapy and detection of tumour persistence or recurrence [8], where inaccuracies in measured ADC values could have significant consequences.

The aim of the current study was to investigate the effect of motion on the accuracy of ADC values measured using DWIBS. A motion phantom was therefore developed with relaxation and diffusion properties modelled on the healthy liver with embedded tumours. The phantom was then imaged while static and moving under simulated respiratory cycle.

\section{MATERIALS AND METHODS:}

The phantom was designed to mimic the liver with embedded tumours of varying sizes, and could be moved up to $15 \mathrm{~mm}$ with a motion which mimicked the movement of the liver during respiration. The tissue mimicking materials used to construct the phantom were specifically tailored to mimic the established values of $A D C, T_{1}$ and $T_{2}$ values for healthy and tumurous liver tissue $[9,10]$. The background liver tissue was produced using 3 wt\% agar dissolved in water and doped with $1 \times 10^{-4}$ $\mathrm{M} \mathrm{MnCl}_{2}$, while the tumour mimicking targets were produced using $20 \mathrm{wt} \%$ PolyVinylAlcohol-cryogel (PVA-c) processed through four freeze-thaw cycles. ADC values of approximately 1.9 and $1.2 \times 10^{-3} \mathrm{~mm}^{2} / \mathrm{s}$ and $T_{1}$ and $T_{2}$ values of $685 \mathrm{~ms}, 40$ ms and $815 \mathrm{~ms}, 60 \mathrm{~ms}$ were achieved for background and tumour tissue mimicking material respectively. To optimally replicate the in vivo environment and provide the most robust evaluation of the DWIBS technique, spherical tumour targets were 
produced with diameters of 5.5, 11.5, 16.5 and $25.5 \mathrm{~mm}$, in each case constructed using custom-made spherical silicon, as illustrated in Fig $1 \mathrm{a}$.

To simulate respiratory motion, the phantom was connected via a bellows and extended tubing to the output of a portable ventilator (Oxylog ${ }^{\circledR} 3000$, Drager Medical, Germany). The ventilator was placed outside the magnet room and the tubing passed through a waveguide. The ventilator produced a physiological respiratory waveform which was used to drive a baby test lung, the expansion and contraction of which was capable of moving the phantom $(2.1 \mathrm{~kg})$ by $15 \mathrm{~mm}$ in the zdirection (i.e. along the bore, which corresponds to the main direction of motion of the liver during respiration) on a rig purpose-built for this task (Fig 1b). A mass of up to approximately $10 \mathrm{~kg}$ could be accommodated with this set-up, although heavier phantoms could conceivably be moved by using a ventilator with a greater output pressure. All imaging was performed on a 3T Achieva system (Philips Medical Systems, the Netherlands) using a 6-channel SENSE torso array coil. The DWIBS protocol used a standard SE-EPI technique with: TR/TE/TI $=7200 / 41 / 260 \mathrm{~ms}$, voxel size $=3.6 \times 3.8 \times 4 \mathrm{~mm}^{3}, \mathrm{~b}$-values $=0,1000 \mathrm{~s} / \mathrm{mm}^{2}, \mathrm{NSA}=6$, scan time $=5 \mathrm{~min} 8 \mathrm{~s}$. An accurate ADC measurement protocol was also used, employing an SE-EPI technique with: $\mathrm{TR} / \mathrm{TE}=2400 / 73 \mathrm{~ms}$, voxel size $=2.5 \times 2.4 \times 3 \mathrm{~mm}^{3}, \mathrm{~b}$-values $=0,200,400,600$, 800 and $1000 \mathrm{~s} / \mathrm{mm}^{2}, \mathrm{NSA}=4$ for $\mathrm{b}<500 \mathrm{~s} / \mathrm{mm}^{2}$ and 8 for $\mathrm{b}>500 \mathrm{~s} / \mathrm{mm}^{2}$, scan time $=11 \mathrm{~min} 24 \mathrm{~s}$. Three orthogonal diffusion encoding gradients were used in all diffusion experiments, and all experiments were repeated 10 times.

The ADC values of the tumour targets calculated with the phantom both static and moving by $15 \mathrm{~mm}$ were assessed in two ways. In an effort to duplicate a normal 
radiology approach, a region of interest (ROI) was placed in the $b=1000 \mathrm{~s} / \mathrm{mm}^{2}$ image in the slice which best visualised the tumour and then copied to the ADC map. ROI's were placed in homogenous regions of the target away from boundaries in the chosen slice.

Secondly, the tumour target was automatically segmented from all slices using a program developed in Matlab (The Mathworks, USA). This involved using a Canny filter to detect the edges of the target due to changes in intensity of pixels and using this outline to mask out the target in all slices where it was present in the $b=1000$ images. The mask was then applied to the other b-weighted images in order to segment the relevant signal intensity values for the pixels deemed to be in the target as determined by the segmentation. From this the ADC values of all pixels present in a given target were calculated. Histograms were generated of the segmented pixels $A D C$ values in both static and moving situations using bins of $0.05 \times 10^{-3} \mathrm{~mm}^{2} / \mathrm{s}$ for the ADC values of pixels in each target. Analysis of mean, median, skew, kurtosis and histogram width ( $90^{\text {th }}$ percentile $-10^{\text {th }}$ percentile) were calculated from the histograms.

RESULTS:

All targets were visualised in the $b=1000$ images. The single ROI analysis revealed no significant change in the mean value of $A D C$ between the three acquisition protocols with the phantom static or moving by $15 \mathrm{~mm}$. 
The results of a segmentation analysis are shown in Fig 2. This compares the ADC values measured in one experiment for the different-sized targets using the accurate ADC protocol and the DWIBS technique (static and moving by $15 \mathrm{~mm}$ ). Although mean ADC values did not change significantly, standard deviations of the measurements did increase significantly $(p<0.01)$ for all but the $5.5 \mathrm{~mm}$ target, for which all three $A D C$ measurements were significantly greater than what can be considered to be the true ADC value measured in the $25.5 \mathrm{~mm}$ target.

Details of the histogram analyses are presented in Table 1 , showing a significant $(p<$ $0.05)$ difference in the histogram widths for all targets, no difference in kurtosis moments for any of the targets, and significant $(p<0.05)$ differences in the skewness for the two largest targets.

DISCUSSION:

The ADC quantification accuracy of a DWIBS scan has been assessed using a custombuilt motion phantom containing spherical tumour targets embedded in a background material with $T_{1}, T_{2}$ and $A D C$ values closely mimicking those of tumour and healthy liver tissue. It was found that, although the mean ADC values were not affected, a significant increase in the spread of $A D C$ values was measured in an otherwise uniform target tumour. This may be attributed to increased PVE's caused by the motion, although motion-induced EPI-related ghosting artefacts are also likely to play an important role. Higher ADC values consistently measured for the $5.5 \mathrm{~mm}$ target likewise reflect a significant PVE, due to the target having dimensions comparable to the spatial resolution of the acquired DWI images. Additionally this study found that simulated respiratory motion had a marked effect on the shape of 
the histogram, with a significant increase in the histogram width of the distribution of $A D C$ values. Targets imaged while the phantom was static exhibited a core spread of $A D C$ values, which broadened when the phantom was moved, with a decreased peak and an increased number of pixels with ADC values to the right of the peak in the ADC histogram. This can be attributed to partial volume effects as a result of the segmentation procedure including pixels close to the target background interface. However, there are an increased number of pixels introduced with lower ADC values when the phantom is moving. Changes in the ADC profile of a tumour in cancer therapy monitoring experiments may lead to incorrect inferences about the response of the tumour to therapy.

The use of b-values less than $100 \mathrm{~s} / \mathrm{mm}^{2}$ to quantify ADC values in conventional DWIBS protocols is also of concern and should be avoided, given the effect of intravoxel capillary perfusion on the calculated ADC values. However, while the use of b-values of, say, 100 and $1000 \mathrm{~s} / \mathrm{mm}^{2}$, will lead to perfusion-insensitive ADC values which are more reflective of tissue cellularity, they will nevertheless suffer from the same spread in values as observed in this study. Furthermore, while the DWIBS protocol used herein represents that optimised at $3 \mathrm{~T}$ in our institution, other variants have been reported, for example with improved spatial resolution and the use of longer TR values, particularly for $1.5 \mathrm{~T}$ systems where inversion recovery fat suppression has been found to work optimally [11]. The use of better spatial resolution has been a problem at $3 \mathrm{~T}$, due to the increased geometrical distortions introduced into the images because of the larger EPI factor which, coupled with the poorer $B_{0}$ field homogeneity over large fields of view which is typical of $3 T$ systems, 
results in significantly degraded image quality. Nevertheless, the effect of improved spatial resolution and variations in the TR value, perhaps by making it a multiple of the respiratory cycle, warrant further investigation.

\section{CONCLUSIONS:}

$A D C$ values measured using the DWIBS technique in a moving phantom were found to be comparable to those measured using an accurate $A D C$ measurement protocol. However, the widths of the histograms of the measurements increased due to the motion, with many pixels showing ADC values significantly lower and higher than their true values. These findings may be of significance in cancer therapy monitoring experiments where slight changes in tumour heterogeneity may be inferred from subtle changes in ADC histograms.

ACKNOWLEDGEMENTS: The work was financially supported by an institutional grant from the Health Research Board (HRB) Ireland. 
1. Ballon D, Watts R, Dyke JP, Lis E, Morris MJ, Scher HI, Ulug AM, Jakubowski AA (2004) Imaging therapeutic response in human bone marrow using rapid whole-body MRI. Magn Reson Med 52 (6):1234-1238.

2. Takahara T, Imai Y, Yamashita T, Yasuda S, Nasu S, Van Cauteren M (2004) Diffusion Weighted Whole Body Imaging with Background Body Signal Suppression (DWIBS): Technical Improvement Using Free Breathing, STIR and High Resolution 3D Display. Radiat Med 22

$(4): 8$

3. Bammer R (2003) Basic principles of diffusion-weighted imaging. Eur J Rad 45 (3):169-184

4. Murtz P, Krautmacher C, Traber F, Gieseke J, Schild HH, Willinek WA (2007) Diffusionweighted whole-body MR imaging with background body signal suppression: a feasibility study at 3.0 Tesla. Eur Radiol 17 (12):3031-3037.

5. Braithwaite AC, Dale BM, Boll DT, Merkle EM (2009) Short- and Midterm Reproducibility of Apparent Diffusion Coefficient Measurements at 3.0-T Diffusion-weighted Imaging of the Abdomen. Radiology 250 (2):459-465.

6. Kilickesmez O, Bayramoglu S, Inci E, Cimilli T (2009) Value of apparent diffusion coefficient measurement for discrimination of focal benign and malignant hepatic masses. J Med Imaging and Radiat Oncol 53 (1):50-55.

7. Kwee TC, Takahara T, Koh DM, Nievelstein RAJ, Luijten PR (2008) Comparison and Reproducibility of ADC Measurements in Breathhold, Respiratory Triggered, and FreeBreathing Diffusion-Weighted MR Imaging of the Liver. J Magn Reson Imaging 28 (5):11411148.

8. Kwee TC, Takahara T, Ochiai R, Katahira K, Van Cauteren M, Imai Y, Nievelstein RAJ, Luijten PR (2009) Whole-body diffusion-weighted magnetic resonance imaging. Eur J Radiol $70(3): 409-417$.

9. Taouli B, Vilgrain V, Dumont E, Daire JL, Fan B, Menu Y (2003) Evaluation of liver diffusion isotropy and characterization of focal hepatic lesions with two single-shot echo-planar MR imaging sequences: Prospective study in 66 patients. Radiology 226 (1):71-78.

10. de Bazelaire CMJ, Duhamel GD, Rofsky NM, Alsop DC (2004) MR imaging relaxation times of abdominal and pelvic tissues measured in vivo at $3.0 \mathrm{~T}$ : Preliminary results. Radiology 230 (3):652-659.

11. Kwee TC, Takahara T, Ochiai R, Nievelstein RAJ, Luijten PR (2008) Diffusion-weighted whole-body imaging with background body signal suppression (DWIBS): features and potential applications in oncology. Eur Radiol 18 (9):1937-1952. 

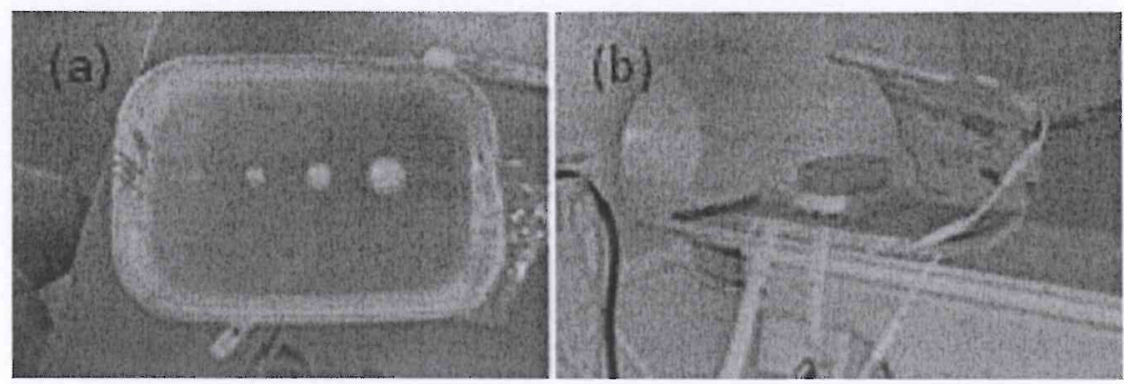

Fig 1 a Photograph showing the positioning of the PVA-c tumour-mimicking target in the background healthy tissue-mimicking material (only half of which was poured in), and Fig. $1 \mathrm{~b}$ the phantom setup just before positioning in the magnet

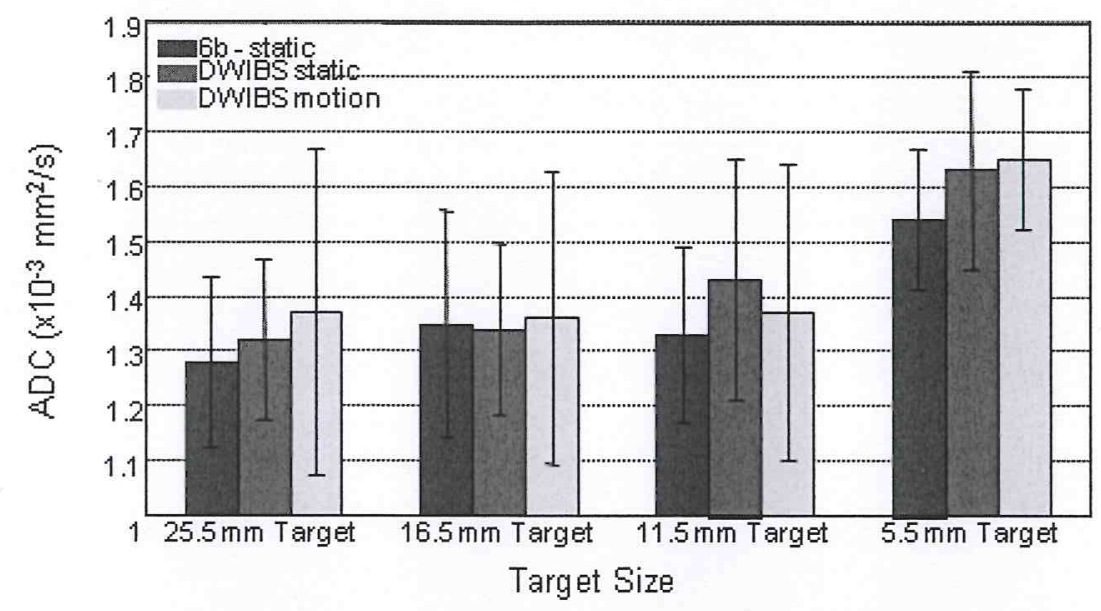

Fig 2 Plots showing the mean ADC values (+/- standard deviation) calculated for pixels that were deemed to be present in a given target by the segmentation routine for one measurement. The standard deviation of the measurements increased significantly $(p<0.01)$ for all but the $5.5 \mathrm{~mm}$ target that was heavily influenced by partial volume effects due to its proximity in size to the acquired spatial resolution 
Table 1: Mean. median, skewness, kurtosis and histogram width (90th percentile - 10th percentile) averaged over ten separate scans for both static and motion conditions of the phantom presented with standard deviations. '*' denotes significant ( $p<0.05$ ) differences between the static and motion conditions. It can be seen that in all targets there was a significant increase in the histogram width attributed to motion.

\begin{tabular}{|c|c|c|c|c|c|c|}
\hline & & $\begin{array}{l}\text { Mean } \\
\times 10^{-3} \mathrm{~s} / \mathrm{mm}^{2}\end{array}$ & $\begin{array}{l}\text { Median } \\
\times 10^{-3} \mathrm{~s} / \mathrm{mm}^{2}\end{array}$ & $\begin{array}{l}\text { Skew } \\
\times 10^{-2}\end{array}$ & Kurtosis & $\begin{array}{l}\text { Hist Width } \\
\times 10^{-3} \mathrm{~s} / \mathrm{mm}^{2}\end{array}$ \\
\hline \multirow{2}{*}{$\begin{array}{l}25.5 \\
\mathrm{~mm}\end{array}$} & Static & $1.42 \pm 0.00$ & $1.46 \pm 0.01$ & $-2.76 \pm 5.11 *$ & $2.41 \pm 0.12$ & $0.52 \pm 0.01$ \\
\hline & Motion & $1.49 \pm 0.10$ & $1.55 \pm 0.11$ & $-39.09 \pm 42.59$ & $2.70 \pm 0.67$ & $1.30 \pm 0.22$ \\
\hline \multirow{2}{*}{$\begin{array}{l}16.5 \\
\mathrm{~mm}\end{array}$} & Static & $1.37 \pm 0.01$ & $1.34 \pm 0.01 *$ & $50.76 \pm 11.77 *$ & $2.59 \pm 0.19$ & $0.51 \pm 0.03$ \\
\hline & Motion & $1.46 \pm 0.14$ & $1.51 \pm 0.18$ & $-35.04 \pm 71.10$ & $2.73 \pm 1.17$ & $1.28 \pm 0.46$ \\
\hline \multirow{2}{*}{$\begin{array}{l}11.5 \\
\mathrm{~mm}\end{array}$} & Static & $1.47 \pm 0.02$ & $1.51 \pm 0.02$ & $-25.57 \pm 10.31$ & $2.08 \pm 0.10$ & $0.56 \pm 0.04$ \\
\hline & Motion & $1.55 \pm 0.14$ & $1.59 \pm 0.19$ & $-9.71 \pm 39.10$ & $1.99 \pm 0.57$ & $1.13 \pm 0.42$ \\
\hline \multirow{2}{*}{$\begin{array}{l}5.5 \\
\mathrm{~mm}\end{array}$} & Static & $1.73 \pm 0.03$ & $1.74 \pm 0.05$ & $-23.05 \pm 25.90$ & $1.98 \pm 0.29$ & $0.38 \pm 0.05$ \\
\hline & Motion & $1.78 \pm 0.30$ & $1.81 \pm 0.37$ & $-26.32 \pm 61.27$ & $2.14 \pm 0.52$ & $0.91 \pm 0.40$ \\
\hline
\end{tabular}

